J. Dairy Sci. 99:2837-2848

http://dx.doi.org/10.3168/jds.2015-10067

(c) 2016, THE AUTHORS. Published by FASS and Elsevier Inc. on behalf

of the American Dairy Science Association ${ }^{\circledR}$. This is an open access article under

the CC BY-NC-ND license (http://creativecommons.org/licenses/by-nc-nd/3.0/).

\title{
Seasonality of fertility measured by physical activity traits in Holstein cows
}

\author{
Ahmed Ismael, ${ }^{*} \dagger^{1}$ Erling Strandberg, $\dagger$ Britt Berglund, $\dagger$ Anders Fogh, $\ddagger$ and Peter Løvendahl* \\ *Department of Molecular Biology and Genetics, Center for Quantitative Genetics and Genomics, Aarhus University, PO Box 50, DK-8830 Tjele, \\ Denmark \\ †Department of Animal Breeding and Genetics, Swedish University of Agricultural Sciences, PO Box 7023, SE-750 07 Uppsala, Sweden \\ $\ddagger$ Knowledge Center for Agriculture, DK-8200 Aarhus N, Skejby, Denmark
}

\begin{abstract}
Seasonality of female fertility traits, including the interval from calving to first high activity (CFHA), duration of high activity episode (DHA), and strength of high activity episode (SHA) of first estrus, were studied. The physical activity traits were derived from electronic activity tags for 20,794 Holstein cows in 135 commercial Holstein herds in Denmark. Data were categorized in 3 ways: (1) into 4 seasons of calving: winter (January-March), spring (April-June), summer (JulySeptember), and fall (October-December); (2) into 2 seasons: a cold season (October-March) and a warm season (April-September); and (3) into an increasing light season (IL; January-June), where daylight hours gradually increased, and a decreasing light season (DL; July-December), where daylight hours gradually decreased. At the phenotypic level, least squares means of CFHA were highest at $55 \mathrm{~d}$ for cows calving in December and lowest at $31 \mathrm{~d}$ for cows calving in September. The highest least squares means of DHA and SHA were recorded for cows calving in November and lowest for cows calving in May and June. Genetic parameters for all traits were estimated using average information-REML in a bivariate animal model that treated the same trait in different calving seasons as different traits. Heritability estimates for CFHA were highest for the winter season (0.13) and low for the other seasons (0.03-0.04), whereas heritability estimates for DHA and SHA were lowest for winter and highest for fall. Heritability estimates for CFHA for the cold season (0.17) was higher than that for the warm season (0.10). Heritability estimates of CFHA for the IL season (0.12) was higher than for the DL season (0.07), but the opposite pattern was found for DHA and SHA. Genetic correlations $\left(\mathrm{r}_{\mathrm{A}}\right)$ of CFHA between
\end{abstract}

\footnotetext{
Received July 5, 2015.

Accepted December 3, 2015.

${ }^{1}$ Corresponding author: ahmed.ismael@mbg.au.dk or ahmedismael sayed@gmail.com
}

winter and summer $\left(\mathrm{r}_{\mathrm{A}}=0.34 \pm 0.27\right)$, and winter and fall $\left(\mathrm{r}_{\mathrm{A}}=0.65 \pm 0.20\right)$ were significantly lower than unity. The corresponding correlations of DHA and SHA between seasons were all close to unity, except for the correlation of SHA between winter and fall $\left(\mathrm{r}_{\mathrm{A}}=0.36 \pm\right.$ 0.34 ). When the year was split into only 2 seasons, the genetic correlation of CFHA between cold and warm seasons was only moderate $\left(\mathrm{r}_{\mathrm{A}}=0.46 \pm 0.15\right)$ but was slightly stronger between IL and DL seasons $\left(\mathrm{r}_{\mathrm{A}}=0.63\right.$ \pm 0.16 ); both significantly deviated from unity. These results indicate the existence of a genotype by environment interaction for CFHA regardless of calving season classification.

Key words: physical activity, seasonality, female fertility, genotype by environment interaction

\section{INTRODUCTION}

Improved reproductive performance has a substantial effect on the overall profitability of dairy cattle production by decreasing insemination and veterinary treatment costs, shortening the calving intervals, and lowering the rate of involuntary culling (Sewalem et al., 2008). However, a decline of fertility has been observed and it could be caused by many factors, including the antagonistic genetic relationship between reproduction and production traits (Lucy, 2001; Royal et al., 2002; König et al., 2008). This relationship implies that continuous selection for increased milk production will continue to have a negative effect on reproduction traits (Kadarmideen et al., 2000; Berry et al., 2003; König et al., 2008) unless proper account is taken in the breeding program.

Although cattle are not strictly seen as seasonal breeders, previous studies on fertility traits indicated that a large fraction of the variability in reproduction traits is affected by seasonal changes. For example, Hansen and Hauser (1984) reported that cows calving in the fall and winter that received supplementary light were found to have a shorter interval from calving to 
first estrus and a shorter interval from calving to first conception compared with cows receiving only natural lighting hours. Also, Reksen et al. (1999) reported that shorter days open, shorter calving interval, and fewer AI were required per cow for herds exposed to supplementary illumination at night compared with herds without nighttime light in Norwegian Red Cattle. Moreover, days open were longest for cows calving in spring and shortest for fall calvers in US Holsteins (Oseni et al., 2003, 2004). In addition, estrus occurrences are less frequent from November to March than from April to October, with a positive correlation of 0.39 between estrus occurrences and hours (duration) of light (Bülbül and Ataman, 2009). Although the previous results indicated that expression of fertility is sensitive to seasonal changes, little research has been done on genotype by environment interaction $(\mathbf{G} \times \mathbf{E})$ for female fertility within a country. Generally, the studies have found very little evidence for $\mathrm{G} \times \mathrm{E}$ and most genetic correlations between environments were close to unity (Kolmodin et al., 2002; Windig et al., 2006; Strandberg et al., 2009).

Genotype by environment interaction exists when the ability to change the phenotype in response to changes in the environment differs among animals (Falconer and Mackay, 1996). The common ways to investigate the existence of $\mathrm{G} \times \mathrm{E}$ are to use a multiple-trait approach or by using the reaction norm approach with a random regression model. The multiple-trait approach can be used when the environment is divided into distinct classes. A clear representation of the application of the multiple-trait approach is using the multiple across-country evaluation (MACE), where each country is considered as a different environment and the correlation of the same trait expressed in different countries is estimated (Schaeffer, 1994). The expressions of the trait in different classes are analyzed as different traits and the existence of $\mathrm{G} \times \mathrm{E}$ interaction is identified by an estimate of genetic correlation significantly different from unity (Falconer, 1952; Falconer and Mackay, 1996). The multiple-trait approach has been used to estimate the genetic correlation for fertility traits in different countries. Genetic correlation for the interval from calving to first insemination, days open, and interval from first to last insemination were estimated between Canada, United States, Spain, Belgium, Switzerland, Germany-Austria evaluations, and joint Nordic evaluation (Denmark-Sweden- Finland) and were found not to differ significantly from unity (Nilforooshan et al., 2009). On the other hand, genetic correlations less than unity were found for age at first calving between Brazil and Colombia, for days open between summer and fall calving cows in the United States, and for calving interval, interval from calving to last insemination, and interval from first to last insemination between organic and conventional dairy herds in Sweden (Cerón-Muñoz et al., 2004; Oseni et al., 2004; Sundberg et al., 2010).

Random regression models have been used to describe effects that change gradually over a continuous scale, where the genotype effect is modeled as a function of the environment, called the reaction norm, which results in heterogeneous variance components and heritability with the change of the environment (Kolmodin et al., 2002; Schaeffer, 2004). For example, Ravagnolo and Misztal (2002) proposed a model to quantify the effect of temperature-humidity index (THI) on nonreturn rate in Holstein cows and obtained heterogeneous heritability estimates with changing THI. Other studies used calving month to develop a heat index (Oseni et al., 2004; Boonkum et al., 2011) and found a phenotypic change of days open in response to calving month. Furthermore, the heritability of days open was heterogeneous across calving months - highest in summer and lowest in winter.

Because traditional measures of female fertility are lowly heritable, they are difficult to improve by genetic selection (Hou et al., 2009; Pszczola et al., 2009). For example, the interval from calving to first insemination is a measure of the ability of a cow to return to cyclic estrus after calving, and the heritability estimate of this trait in Nordic dairy cattle is only 0.07 (Muuttoranta et al., 2015). On the other hand, objective measures that directly reflect the physiological or behavioral changes have been used to overcome the low heritability of that trait. For instance, the interval from calving to commencement of luteal activity (C-LA) is an objective measure of return to cyclicity after calving and it can be determined using progesterone profiles. This trait has heritability estimates of 0.13 to 0.16 , which is considerably higher than estimates for traditional measurements of fertility in dairy cows (Veerkamp et al., 2000; Petersson et al., 2007; Berry et al., 2012). Another alternative measure of fertility is the interval from calving to first high physical activity (CFHA). This can be determined from electronic pedometers or activity tags that use behavioral changes to detect estrus in dairy cows and has heritability estimates of 0.12 to 0.18 (Løvendahl and Chagunda, 2009; Ismael et al., 2015). In both studies, the authors suggested the use of activity tags to measure more estrus-related traits; for example, the strength of high activity as an indicator for estrus strength (SHA, $h^{2}=0.04$ to 0.06 ) and the duration of high activity as an indicator for estrus duration (DHA, $h^{2}=0.02$ to 0.08). Those traits are, to our knowledge, not measured today in breeding programs, except for Sweden, where a breeding value for 
a subjectively scored estrus strength has been included in the Swedish total merit index since 1999 (Svensk Mjölk, 1999).

The previously conducted studies showed that seasonal changes affect both the phenotypic expression and the genetic parameters of traditionally measured fertility traits. The higher heritability and widespread use of activity tags makes it important to study seasonal effects on the alternative fertility traits based on physical activity devices.

The objective of this study was therefore to investigate the effect of calving season on the genetic parameters of 3 fertility traits (the interval from calving to first high activity and the duration and strength of the first high activity episode) derived from activity tags.

\section{MATERIALS AND METHODS}

\section{Animals and Data}

Female fertility traits in the present study were CFHA (Løvendahl and Chagunda, 2010; Ismael et al., 2015), as well as DHA and SHA, all based on data from physical activity meters. The physical activity traits were based on raw data for 42,096 Danish Holstein cows collected from 164 commercial dairy herds with automatic milking systems and activity monitoring devices from January 2010 to January 2015. The pedigree was built using a sire-dam structure and tracing back as many generations as possible in the Nordic Cattle database (NAV, Skejby, Denmark). The total pedigree file included 134,532 animals. Physical activity data were measured by electronic activity tags fitted on neckbands (Lely Qwes-H or Qwes-HR, Lely Industries BV, Maassluis, the Netherlands). Cows' physical activity information was measured as the number of electronic impulses per 2-h bin initiated by changes in acceleration due to head and neck movements. Data were edited using the procedure as described by Ismael et al. (2015). Only records from cows in parities 1 to 3 were included in the analysis, and only a single record per cow was included in the current analysis. If a cow had data for more than one parity, only the earliest parity was used. To be eligible for inclusion in the analysis, physical activity recording had to include the period from 15 to $155 \mathrm{~d}$ postpartum. Within this period, every cow had to have at least 45 consecutive days of recorded activity. This rule was applied because different farms had different start times for physical activity recording.

After editing, the final data set contained activity traits for 20,794 Holstein cows housed in 135 commercial dairy herds.

Physical activity data were processed by the exponential smoothing algorithm previously used by Ismael et al. (2015), where the 3 estrus activity traits were defined as follows: CFHA = number of days from calving to day of first high activity, DHA = time in hours between start and end of each episode, and SHA = the mean of the 2 highest deviation values during the episode; SHA was ln-transformed after adding 1.0 before statistical analysis.

\section{Statistical Analysis}

Three sets of analysis were performed on CFHA, DHA, and SHA. The first analysis was a fixed effects model to test for the phenotypic effect of month of calving using the HPMIXED procedure in the SAS package (SAS 9.3, SAS Institute Inc., Cary, NC). The model used was

$$
\mathrm{y}_{i j k l m}=\mu+h_{i}+p_{j}+y m_{k}+m c_{l}+\mathrm{e}_{i j k l m}
$$

where $\mathrm{y}_{i j k l m}$ is the trait value for cow $m$ in the herd $i$, parity $j$, with high activity episode in the year-month $k$, during calving month $l ; \mu$ is the intercept; $h_{i}$ is the fixed effect of herd $i$ ( $i=135$ herds); $p_{j}$ is the fixed effect of parity $j(j=1$ to 3$) ; y m_{k}$ is the fixed effect of yearmonth $k$ of high activity episode ( $k=61$ levels); $m c_{l}$ is the fixed effect of month of calving $l(l=1$ to 12$)$; and $\mathrm{e}_{i j k l m}$ is the random residual, $\sim N D\left(\mathbf{0}, \mathbf{I} \sigma_{e}^{2}\right)$, where $\mathbf{I}$ is the identity matrix and $\sigma_{e}^{2}$ is the residual variance.

The second analysis fitted a univariate animal model to each trait in each season. The model used was

$$
\mathrm{y}_{i j k l m}=\mu+h_{i}+p_{j}+y m_{k}+a_{l}+\mathrm{e}_{i j k l m},
$$

where $\mathrm{y}_{i j k l m}$ is the trait value in a certain season for cow $m$ in the herd $i$, parity $j$, with high activity episode in the year-month $k ; \mu$ is the intercept; $h_{i}$ is the fixed effect of herd $i$ ( $i=135$ herds); $p_{j}$ is the fixed effect of parity $j(j=1$ to 3$) ; y m_{k}$ is the fixed effect of yearmonth $k$ of high activity episode ( $k=61$ levels); $a_{l}$ is the random genetic effect, $\sim N D\left(\mathbf{0}, \mathbf{A} \sigma_{a}^{2}\right)$, where $\sigma_{a}^{2}$ is the additive genetic variance and $\mathbf{A}$ is the additive genetic relationship matrix $(l=1$ to 20,794$)$, and $\mathrm{e}_{i j k l m}$ is the random residual, $\sim \operatorname{IND}\left(\mathbf{0}, \mathbf{I} \sigma_{e}^{2}\right)$, where $\mathbf{I}$ is the identity matrix and $\sigma_{e}^{2}$ is the residual variance.

Seasonality of traits was defined by partitioning the data in 3 different ways: (1) into 4 subsets based on season of calving as follows: winter (January-March); spring (April-June); summer (July-September); and fall (October-December); (2) into a cold season (October-March) and warm season (April-September); and (3) into increasing light season (IL; January-June), where there is a gradual increase of daylight hours from 


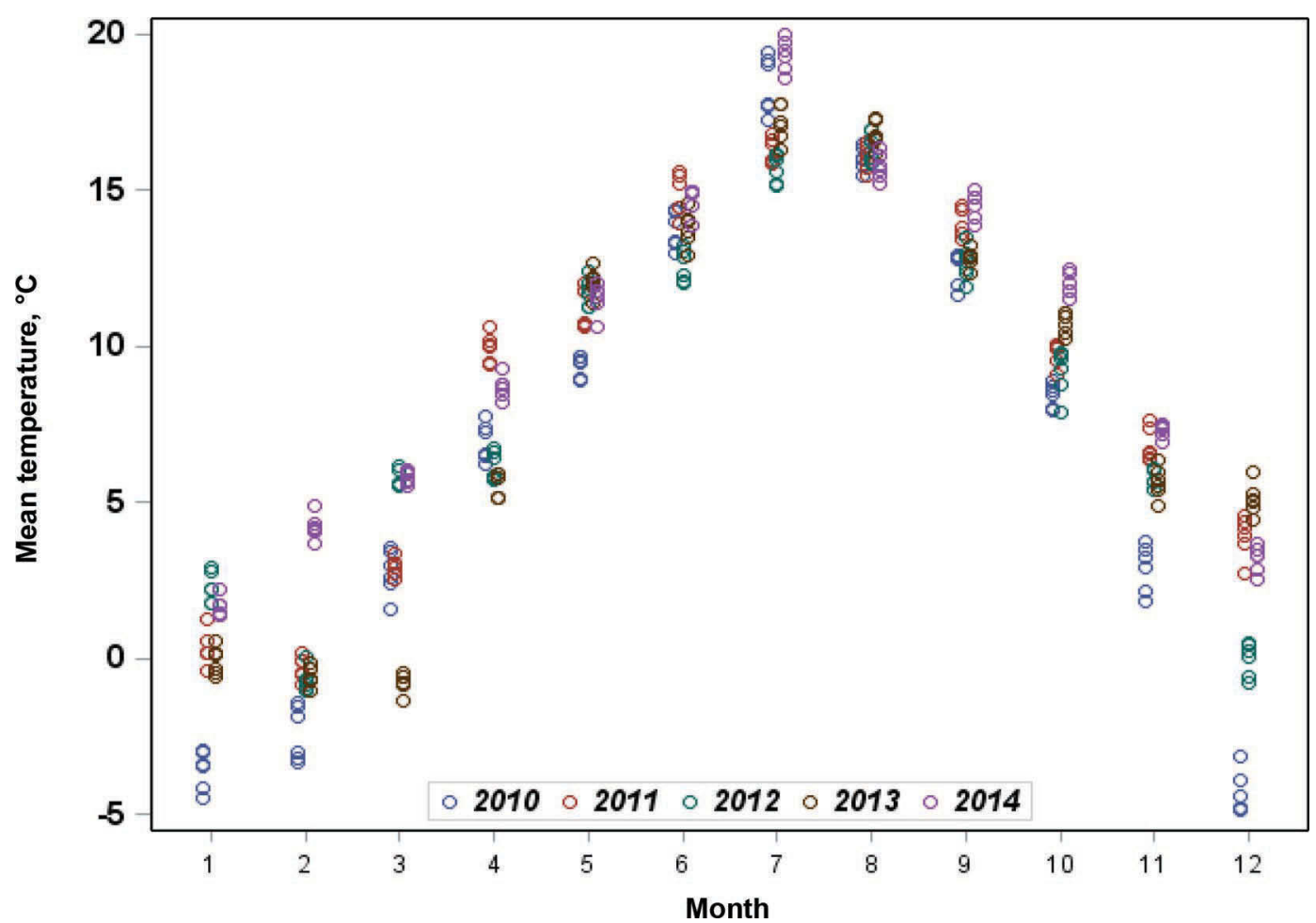

Figure 1. Mean monthly temperature from 6 weather stations in different geographic regions in Denmark for the period from 2010 to 2014.

0700 to $1700 \mathrm{~h}$, and a decreasing light season (DL; July-December), where there is a gradual decrease of daylight hours from 1700 to 0700 h. Figure 1 shows the average monthly temperature from 6 weather stations covering representative geographic regions in Denmark for the period from 2010 to 2014 (climate data were kindly provided by the Climate and Bioenergy section at Department of Agroecology, Aarhus University).

The third analysis performed was an extension of model [2] to a bivariate model to estimate the genetic correlation for each trait between the various calving seasons to investigate for possible existence of $\mathrm{G} \times \mathrm{E}$ interaction. The variance-covariance structure for this model is

$$
\operatorname{Var}\left[\begin{array}{l}
\mathbf{a}_{1} \\
\mathbf{a}_{2}
\end{array}\right]=\left[\begin{array}{cc}
\mathbf{A} \sigma_{a_{1}}^{2} & \mathbf{A} \sigma_{a_{1} a_{2}} \\
\mathbf{A} \sigma_{a_{2} a_{1}} & \mathbf{A} \sigma_{a_{2}}^{2}
\end{array}\right],
$$

where $a_{1}$ and $a_{2}$ represent the additive genetic merit of the cow in first and second season; $\sigma_{a_{1}}^{2}$ and $\sigma_{a_{2}}^{2}$ are the additive genetic variances for the traits in different seasons; and $\sigma_{a_{1} a_{2}}$ is the additive genetic covariance for the traits across seasons. Because the correlated traits are not recorded on the same animals, no environmen- tal covariance exists between traits, and the residual variance-covariance matrix is

$$
\operatorname{Var}(e)=\mathbf{R}=\left[\begin{array}{cc}
\sigma_{e_{1}}^{2} & \mathbf{0} \\
\mathbf{0} & \sigma_{e_{2}}^{2}
\end{array}\right],
$$

where $\mathbf{R}$ is the residual covariance matrix between traits, and $\sigma_{e_{1}}^{2}$ and $\sigma_{e_{2}}^{2}$ are the residual variances for the trait in different seasons. Genetic correlations were considered significantly different from unity if they deviated by more than $1.645 \times$ standard error from 1 , where the value 1.645 corresponds to the one-sided $5 \%$ cut off point of the normal distribution. For all models, variance and covariance components were estimated using average information (AI)-REML procedure as implemented in the DMU package (Madsen and Jensen, 2010).

\section{RESULTS}

In this study, physical activity data were used to study seasonal effects on 3 activity-based estrus traits: CFHA, DHA, and SHA in loose-housed Holstein cows. The effects of season of calving on the phenotypic 
expression and genetic parameters of traits were estimated. Finally, genetic correlations for each trait in different calving seasons were obtained to investigate possible $\mathrm{G} \times \mathrm{E}$ interactions.

\section{Effect of Month of Calving on Physical Activity Traits}

An overall summary of number of records in each season, means, standard deviations, minimum and maximum for CFHA, DHA, and SHA in different calving seasons is shown in Table 1 . The CFHA trait was longest for December calvings with $55 \mathrm{~d}$, and shortest for September calvings with $31 \mathrm{~d}$ (Figure 2); DHA was longest for November calvings with $8.8 \mathrm{~h}$, and shortest for June calvings with $8.2 \mathrm{~h}$ (Figure 3); and SHA was strongest for October calvings with 1.0 ln-units, and weakest for May calvings with 0.91 ln-units (Figure 4).

When months of calving were grouped into 4 seasons of calving (Table 1), CFHA was longest for winter and spring calvings, whereas summer calvings had the shortest CFHA; DHA and SHA followed the same pattern, as shown in Figures 3 and 4. When grouping months of calvings into cold and warm or into IL and DL (Table 1 ), cows that calved in the cold season had CFHA 3 d longer than cows calving in the warm season $(P<$ 0.01 ), whereas no significant differences were found for DHA or SHA between cold and warm calving seasons. Cows that calved in the IL season had CFHA $8 \mathrm{~d}$ longer than cows that calved in DL $(P<0.01)$, whereas both DHA and SHA were highest for DL season $(P<0.01)$.

\section{Variance Components and Heritability Estimates}

The genetic parameters estimated for each trait in differently defined seasons are shown in Table 2. For CFHA, both additive genetic variance and heritability were highest for winter calvings $\left(h^{2}=0.13\right)$ and lowest for spring calvings $\left(h^{2}=0.03\right)$. Additive genetic variance and heritability estimate for CFHA for cold calving season were higher $\left(h^{2}=0.17\right)$ than those for the warm calving season $\left(h^{2}=0.10\right)$. Additive genetic variance and heritability estimate for CFHA for IL were about twice as high $\left(h^{2}=0.12\right)$ as those for DL $\left(h^{2}=0.07\right)$.

For DHA and SHA, the highest additive genetic variance and heritability were found for fall calvings and the lowest were found for winter calvings. Heritability of DHA for winter and spring seasons was not significantly different from zero, whereas heritabilities for summer and fall seasons were 0.03 and 0.05 , respectively. Heritability of SHA for winter was not significantly different from zero, whereas it ranged from 0.03 for spring calvings to 0.09 for fall calvings. Additive genetic variance and heritability estimates for DHA and
SHA for cold and warm calving seasons were almost similar across seasonal classifications. The heritability for DHA for IL season was close to zero but higher for DL season $\left(h^{2}=0.05\right)$. The heritability for SHA for DL season was almost larger for the IL season than for DL (0.05 and 0.03, respectively).

\section{Genetic Correlations Between Traits in Different Seasons}

Genetic correlations for CFHA, DHA, and SHA are shown in Table 3. For CFHA, genetic correlations $\left(\mathbf{r}_{\mathbf{A}}\right)$ between calving seasons were not significantly different from unity except those between winter and summer and between winter and fall $\left(\mathrm{r}_{\mathrm{A}}=0.34\right.$ and 0.65 , respectively). For DHA, none of the genetic correlations found between calving seasons were significantly different from unity. For SHA, only the genetic correlation between winter and fall seasons was significantly different from unity $\left(\mathrm{r}_{\mathrm{A}}=0.36\right)$.

The genetic correlation between CFHA in warm and cold calving seasons was moderate and significantly different from unity (0.46), as was the genetic correlation between CFHA in IL and DL calving seasons (0.63). None of the genetic correlations for DHA and SHA in warm versus cold or IL versus DL calving seasons were significantly different from unity.

\section{DISCUSSION}

In this study, month of calving was found to have a significant phenotypic effect on the expression of CFHA, DHA, and SHA. Seasons of calving affected variance components and heritability estimates for the traits. A significant $G \times E$ interaction was found for CFHA between warm and cold and between IL and DL calving seasons and was supported by results of the multiple-trait approach.

Use of activity monitoring devices such as pedometers or activity tags as indicators of estrus behavior is reported in several studies (At-Taras and Spahr, 2001; Roelofs et al., 2005; Løvendahl and Chagunda, 2010). In these studies, detection rates of estrus of $87 \%$ with daily error rates of $0.93 \%$ were reported. In our study, we validated heat detection on a subset of cows that had undergone successful AI, based on birth of a calf or a confirmed pregnancy, and we found a detection rate of $87 \%$ and a daily error rate of $0.9 \%$, in agreement with previous results.

\section{Effect of Month of Calving on Physical Activity Traits}

Cows calving in December had their first highactivity episode $24 \mathrm{~d}$ later than those calving in Sep- 
ISMAEL ET AL.

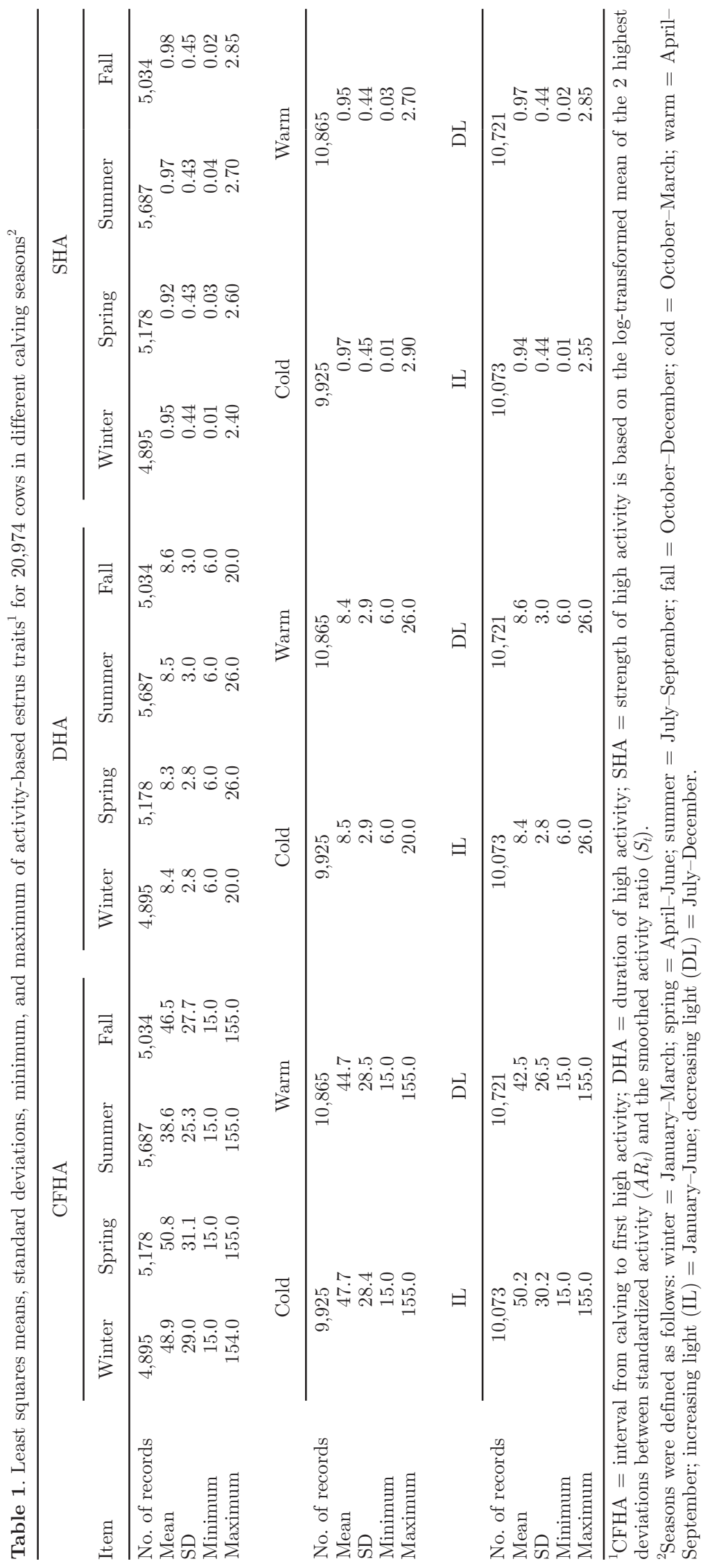




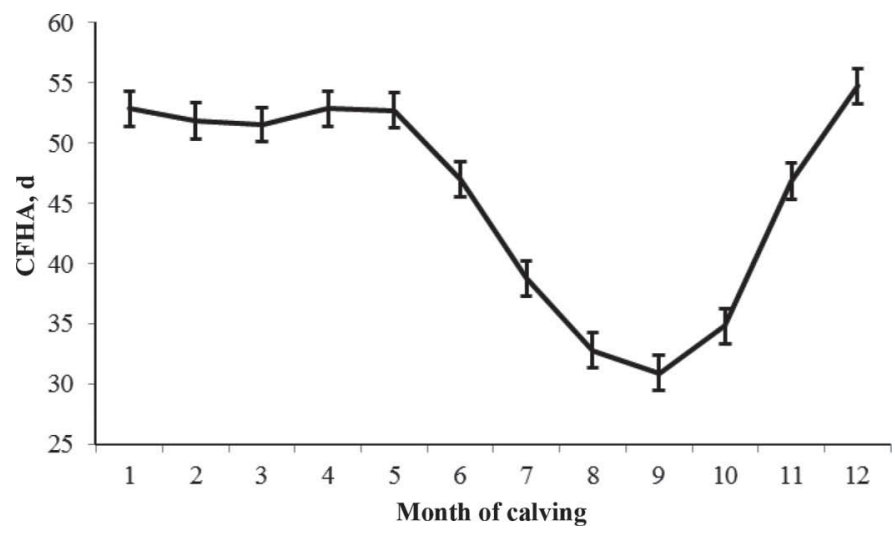

Figure 2. Effect of month of calving on the interval (d) from calving to first high activity (CFHA; least squares means $\pm \mathrm{SE}$ ).

tember. Moreover, CFHA was consistently high for December to May calvings, and then decreased from June to September before increasing again (Figure 2). The decrease in CFHA from May to September was associated with the increase of both daylight length and temperature, whereas the increase of CFHA from September to December was associated with the decrease of both daylight length and temperature in Denmark. Seasonality effects on CFHA were also obvious when months of calving were grouped into 4 seasons of calving, where cows calving in summer had CFHA $12 \mathrm{~d}$ shorter than that of cows calving in spring (Table 1). Similar relationships between calving season and C-LA were reported by Royal et al. (2002) and Petersson et al. (2006), where C-LA was shorter for cows calving during the summer season compared with those calving in the winter season by 8.0 and $10.5 \mathrm{~d}$ in the UK and Sweden, respectively. Moreover, Hansen and Hauser (1983) reported that first-parity cows calving in winter had a 46-d-longer interval from calving to first estrus

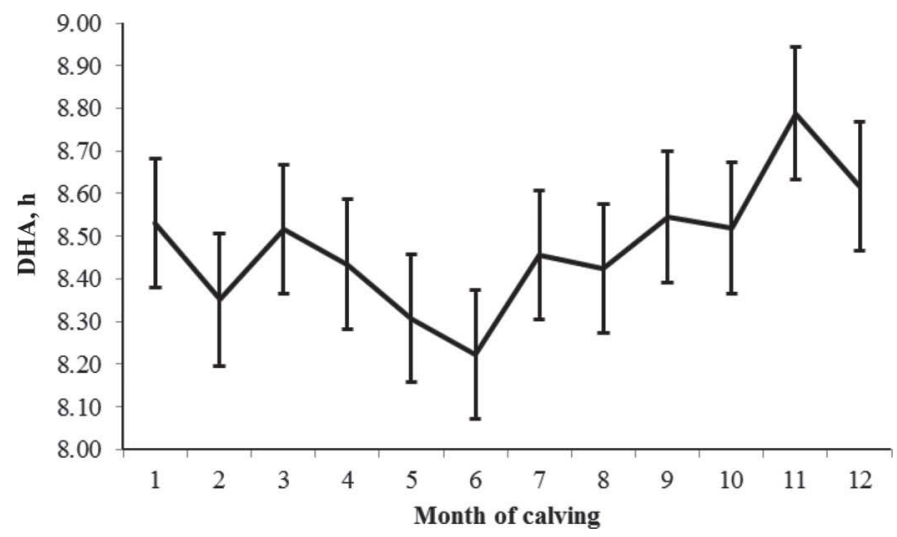

Figure 3. Effect of month of calving on duration (h) of high activity (DHA; least squares means $\pm \mathrm{SE}$ ). and from calving to conception than those calving in summer. In US Holsteins, Oseni et al. (2004) reported a similar relationship between days open and season of calving, where spring calvers remained open $27 \mathrm{~d}$ longer than summer calvers. However, these studies did not specify the environmental components responsible for seasonal variations for the interval from calving to first estrus. In our understanding, the seasonal components responsible for this variation in the current study were the combined effects of daylight length and temperature. Cold temperatures could affect estrus behavior negatively by decreasing mounting behavior (Gwazdauskas et al., 1990). This might decrease the possibility of estrus detection and consequently increase CFHA. This relationship between seasonal variations for DHA and SHA can be seen in Table 2: the lowest means for DHA and SHA were found for spring calvers $(P<0.05)$ that also had the longest CFHA (51 d). Another possible factor that could affect CFHA is day length. However, for housed cows, day length is often prolonged using supplementary light. Reksen et al. (1999) reported that days open and calving interval were $4 \mathrm{~d}$ shorter, AI number per cow was 0.07 less, and the nonreturn rate was $3.1 \%$ greater for herds exposed to a photoperiod greater than $12 \mathrm{~h}$ in Norwegian dairy cows than for cows given no supplementary light. Hansen and Hauser (1984) reported that cows receiving 18 $\mathrm{h}$ of light had fewer days from calving to first estrus, shorter interval from calving to conception, and higher conception rate compared with the cows that did not receive supplementary light. Danish recommendations of cattle housing design regarding daylight period for dairy cows inside automatic milking system barns recommended extension of daylight with artificial light to 14 to $16 \mathrm{~h}$ in winter, at an intensity of $200 \mathrm{~lx}$, and 8 to $10 \mathrm{~h}$ of nighttime light, at an intensity of $5 \mathrm{~lx}$ (SEGES, 2012). Under normal climatic conditions in Denmark,

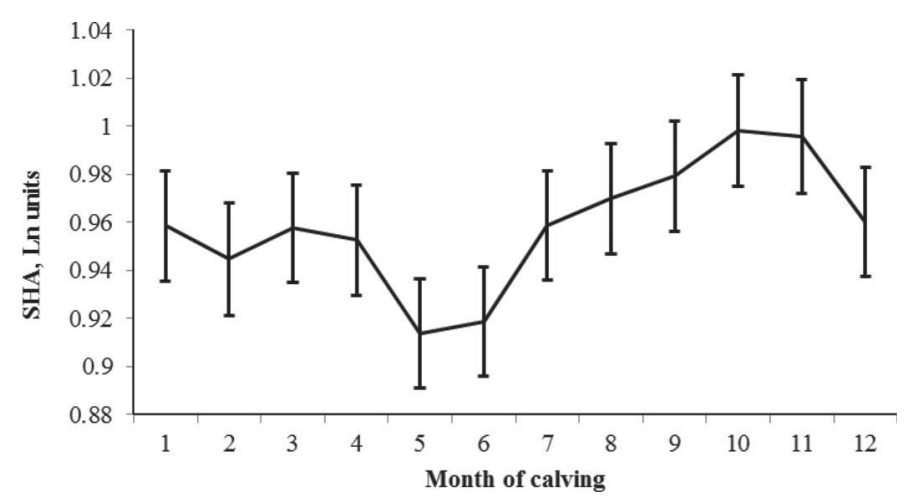

Figure 4. Effect of month of calving on strength (ln units) of high activity (SHA; least squares means $\pm \mathrm{SE}$ ). 
ISMAEL ET AL.

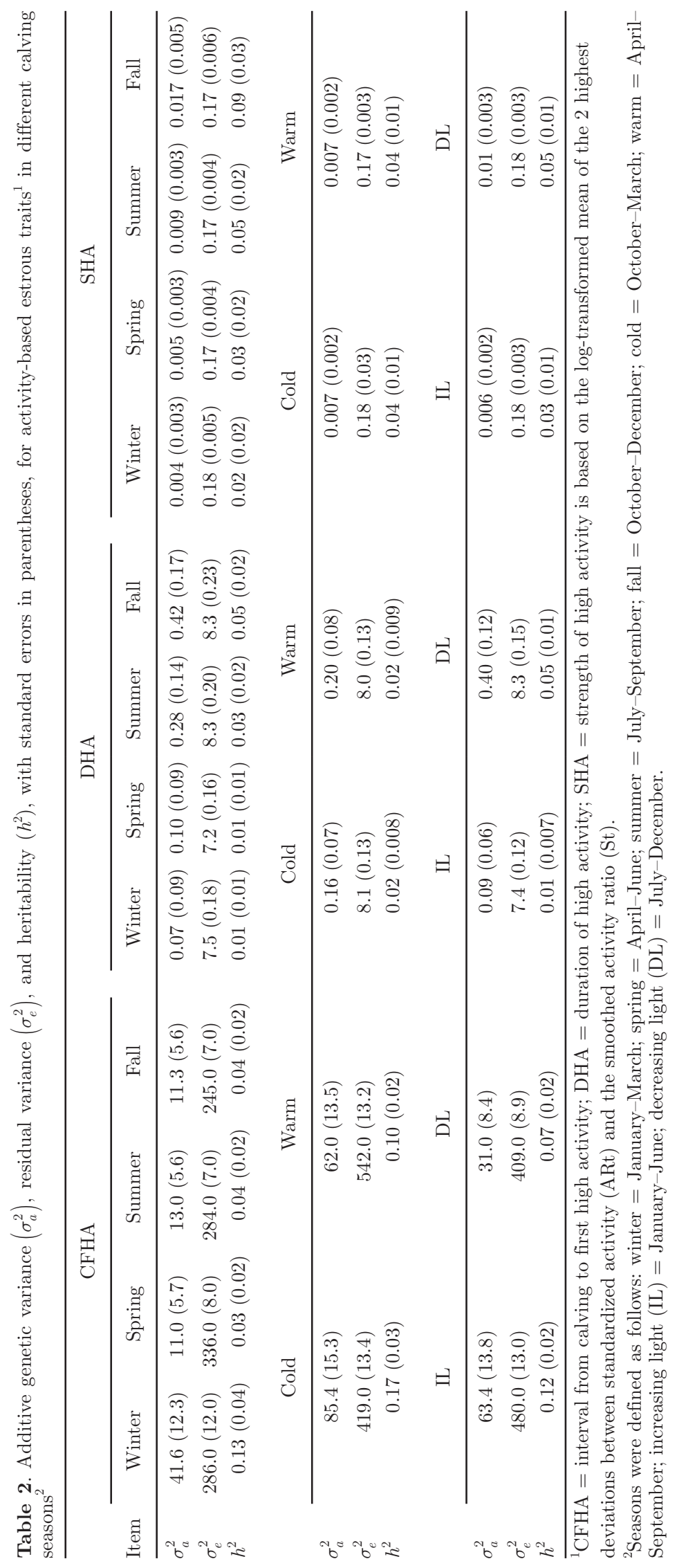




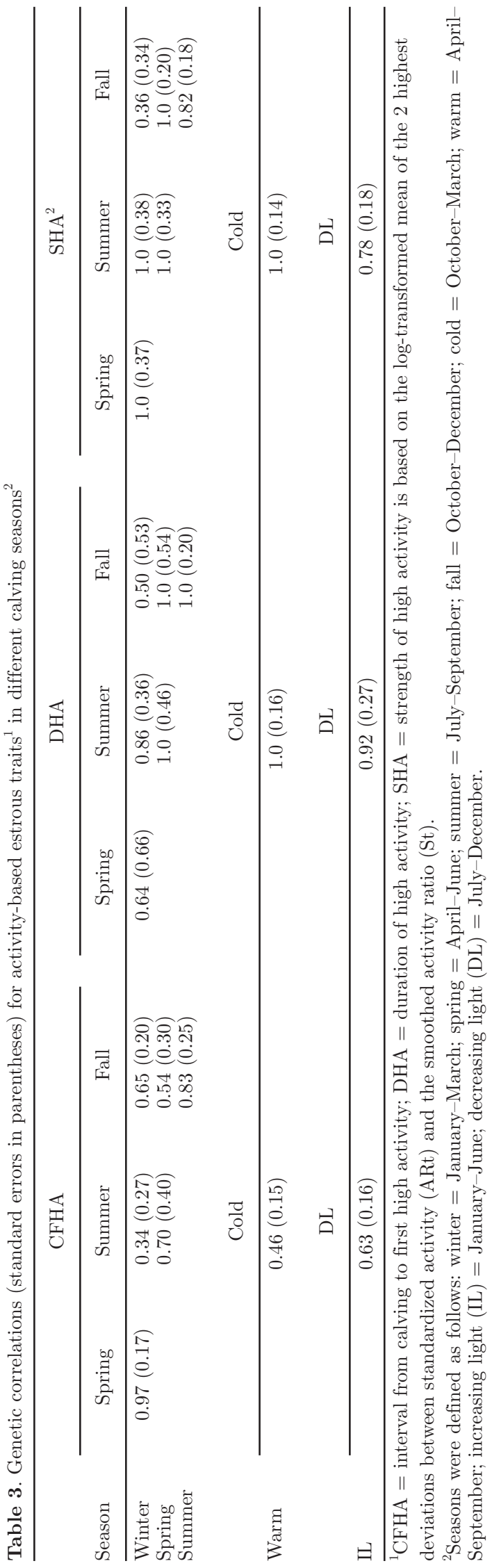

heat stress is unlikely, as shown in Figure 1, where the monthly average temperature from 6 different locations in Denmark for 5 yr (2010-2014) is summarized. Furthermore, Denmark is a small country where geographic location has only a minor effect on weather conditions. Besides, the average monthly temperature to which the cows were exposed remained in the thermo-neutral zone for lactating cows (Fuhrer and Gregory, 2014). Unfortunately, in the current study, information about length and intensity of the extended light used by each farm was not available. If that information had been available and there was variation between farms of daylight length and intensity of artificial light used, it might be possible to use a reaction norm approach to model effects of length and intensity of light as an environmental descriptor.

At the phenotypic level, cows calving in November had DHA $0.6 \mathrm{~h}$ longer than cows calving in June, with a decreased monthly pattern from November to its minimum for June calvings (Figure 3). Strength of high activity followed the same seasonal pattern as DHA (Figure 4). Little research has been done on the relationship between estrus behavior and changes in daylight length. However, the same trend was observed in ongoing studies of DHA based on visual inspection of estrus behavior [S. Nyman, S. E. Malm, H. Gustafsson, and B. Berglund (Swedish University of Agricultural Sciences), unpublished data]. Bülbül and Ataman (2009) found that estrus occurrence was less frequent from November to March than from April to October. The same authors found a positive correlation of 0.39 between estrus occurrences and the duration of daylight. Gwazdauskas (1985) reported a 5-h decrease in observed estrus duration with increased temperature from mild $\left(<22^{\circ} \mathrm{C}\right)$ to hot conditions $\left(>28^{\circ} \mathrm{C}\right)$. Looking at the full spectrum, Gwazdauskas et al. (1983) reported that intensity of mounting activity during estrus, expressed as the number of mounts per hour, was $50 \%$ lower during very cold weather (below $-10^{\circ} \mathrm{C}$ ) and increased to maximum when the daily temperature increased to $25^{\circ} \mathrm{C}$ and then decreased when the temperature increased above $30^{\circ} \mathrm{C}$. Therefore, we speculate that changes in both DHA and SHA might be associated with changes in daylight length more than the changes in temperature, because the temperature in June and November remained within the thermo-neutral zone for lactating cows (Fuhrer and Gregory, 2014) as shown in Figure 1, whereas there was a 10 -h difference in average monthly daylight length between June and November.

\section{Variance Components and Heritability Estimates}

For CFHA, heritability, genetic variance, and residual variances were not constant across seasons. The highest 
heritability was obtained for winter calvings and associated with the highest genetic variance, whereas the lowest heritability was obtained for spring calvings and associated with the lowest genetic variance and highest residual variance. The same relationship was observed in the other seasonal classifications, where the heritability estimate for the cold calving season was $70 \%$ higher than the estimate for the warm calving season and the heritability estimate for IL calving season was twice the heritability estimate of DL calving season. It was clear that the high heritability estimates of the cold and IL calving seasons were mainly reflecting large genetic variance. These estimates indicate that the seasonal variability in CFHA has genetic components. These findings are in agreement with Oseni et al. (2004), who reported that for days open in US Holstein, the genetic variance for winter calvings was 3 times the genetic variance for fall calvings. Also, the largest genetic variance was associated with largest residual variance for winter calvings, whereas for spring and summer calvings, it was associated with the smallest residual variance. This jointly led to the highest heritability estimate for spring calvings and the lowest estimate for fall calvings.

Genetic variance and heritability of DHA was generally low but increased from winter through spring and summer, with the highest estimate for the fall calving season. Genetic variance and heritability of SHA followed the same pattern as for DHA. Variance components and heritability estimates for both DHA and SHA were not affected by cold and warm calving seasons but were higher for DL compared with IL calving season.

The major consequence of heterogeneity of genetic variances is that selection in the average environment using EBV leads to different selection responses in different environments (Falconer and Mackay, 1996). For example, if selection for shorter CFHA were performed in an environment where cows calved in IL season, then the response to selection would be different in the environment where cows calved in DL season. This issue was introduced clearly by Calus et al. (2005, 2006), who found that selection for higher fertility and lower SCS gained higher selection responses in herds with, on average, poorer fertility and higher SCS. Moreover, significant heterogeneity of heritability estimates for the traits across environments can cause heterogeneity of accuracies of animals tested in different environments (Hill et al., 1983).

\section{Genetic Correlations Between Traits in Different Seasons}

Genetic correlations of CFHA between winter on the one hand and summer and fall on the other, between cold and warm seasons, and between IL and DL calving seasons were lower than unity, indicating that $\mathrm{G} \times \mathrm{E}$ interactions do exist. Consequently, selection for shorter CFHA when this form of $\mathrm{G} \times \mathrm{E}$ is ignored limits the rate of genetic progress. Robertson (1959) suggested that if genetic correlation of the traits in different environments is $<0.8$, the $\mathrm{G} \times \mathrm{E}$ interaction should be considered biologically important. Recently, Mulder et al. (2006) reported that, for traits with correlations $<0.61$ between environments, it could be more efficient to run 2 separate breeding programs specific to each environment. However, running 2 breeding programs is not appropriate when farmers prefer cows that are fertile year round. Alternatively, this could suggest the use of specific breeding values for each calving seasons, but that approach increases the complexity of selection and may not benefit progress in the population. On the other hand, genetic correlations of CFHA between other seasons indicated that the trait in these broader calving seasons is under the control of the same genes and that the $\mathrm{G} \times \mathrm{E}$ interaction is less important. Another option would be to select cows that have superior breeding values in all environments; in other words, those that are robust to seasonal effects.

Genetic correlations of DHA and SHA between different calving seasons were not significantly different from unity except for that between SHA in winter and fall seasons, indicating that these traits are less affected than CFHA by the seasonal variations and that they are under the control of the same genes in different seasons.

When months of calving were grouped into 4 seasons, a significant $\mathrm{G} \times \mathrm{E}$ interaction was found for $\mathrm{CFHA}$ and SHA based on the genetic correlation estimates between calving seasons. However, these estimates are likely to be biased downward because of the low heritability estimates of the traits and the small data set. Such bias might indicate the existence of a strong $G \times$ E interaction when it really does not exist (Sae-Lim et al., 2010). To overcome this issue, more data might be required for further validation of the obtained results.

In the present study, it was difficult to align the obtained results with other research because only a few studies have reported the $\mathrm{G} \times \mathrm{E}$ interaction for fertility traits in dairy cattle. To the best of our knowledge, no other research has been done on the $\mathrm{G} \times \mathrm{E}$ interaction for seasonality of estrus traits measured by physical activity. The research reported previously on $\mathrm{G} \times \mathrm{E}$ interaction for fertility traits has mainly focused on the effect of heat stress, which may be a consequence of seasonal variation or be confounded with the classification of the seasonal components in the different seasons (Oseni et al., 2004). However, the analysis of larger 
data sets is required to fully support the present findings, especially with the 4-season classification.

The early return to cyclic estrus after calving is one of the most important factors determining the length of calving interval, which is the primary trait used to evaluate a cow's reproductive efficiency. Further investigations into the relationship between CFHA and calving interval are needed for the future use of CFHA as an indicator trait for the calving interval as a breeding goal trait.

For this study, the mechanisms of action underlying seasonal variations for estrus traits are not well known and appear to be confounded for light and temperature. Perhaps more controlled experiments are required to study these factors, including temperature, humidity, nutrition, daylight length, supplementary illumination, level of production, and seasonal changes for reproductive hormones with respect to calving season. For G $\times \mathrm{E}$ interaction effects, in case of the scaling effect for the traits in different calving seasons, corrections of the EBV to an average environment would be sufficient without any consequence on selection decisions (Meuwissen et al., 1996). On the other hand, in the case of reranking of animals between environments (e.g., for CFHA in cold vs. warm or IL vs. DL environments), it could be possible to select for superior cows for each environment. However, the feasibility of this approach should be evaluated carefully.

\section{CONCLUSIONS}

The trait CFHA was more influenced by seasonal variation than the traits DHA and SHA. Heterogeneous genetic variation was found for CFHA, DHA, and SHA with respect to all seasons, and there were clear indications of genotype by environment interaction for CFHA between calving seasons, regardless of how the seasons were classified. This implies that if we want to select sires for shorter CFHA, the feasibility of having separate breeding values for given environments versus selection for robustness across environments should be considered as the better option.

\section{ACKNOWLEDGMENTS}

This study is a part of the project "Nordic research network on animal genetic resources in the adaptation to climate change" funded by the AnGR-NordicNET. The authors also acknowledge the Knowledge Center for Agriculture (Skejby, Denmark) for providing the data. The first author is enrolled in the Erasmus-Mundus joint doctorate European Graduate School in Animal Breeding and Genetics "EGS-ABG."

\section{REFERENCES}

At-Taras, E. E., and S. L. Spahr. 2001. Detection and characterization of estrus in dairy cattle with an electronic heatmount detector and an electronic activity tag. J. Dairy Sci. 84:792-798.

Berry, D. P., J. W. M. Bastiaansen, R. F. Veerkamp, S. Wijga, E. Wall, B. Berglund, and M. P. L. Calus. 2012. Genome-wide associations for fertility traits in Holstein-Friesian dairy cows using data from experimental research herds in four European countries. Animal 6:1206-1215.

Berry, D. P., F. Buckley, P. Dillon, R. D. Evans, M. Rath, and R. F. Veerkamp. 2003. Genetic parameters for body condition score, body weight, milk yield, and fertility estimated using random regression models. J. Dairy Sci. 86:3704-3717.

Boonkum, W., I. Misztal, M. Duangjinda, V. Pattarajinda, S. Tumwasorn, and S. Buaban. 2011. Short communication: genetic effects of heat stress on days open for Thai Holstein crossbreds. J. Dairy Sci. 94:1592-1596.

Bülbül, B., and M. B. Ataman. 2009. The effect of some seasonal conditions on oestrus occurrence in cows. Arch. Tierzucht 52:459-465.

Calus, M. P. L., L. L. G. Janss, and R. F. Veerkamp. 2006. Genotype by environment interaction for somatic cell score across bulk milk somatic cell count and days in milk. J. Dairy Sci. 89:4846-4857.

Calus, M. P. L., J. J. Windig, and R. F. Veerkamp. 2005. Associations among descriptors of herd management and phenotypic and genetic levels of health and fertility. J. Dairy Sci. 88:2178-2189.

Cerón-Muñoz, M. F., H. Tonhati, C. N. Costa, J. Maldonado-Estrada, and D. Rojas-Sarmiento. 2004. Genotype x environment interaction for age at first calving in Brazilian and Colombian Holsteins. J. Dairy Sci. 87:2455-2458.

Falconer, D. S. 1952. The problem of environment and selection. Am. Nat. 86:293-298.

Falconer, D. S., and T. F. C. Mackay. 1996. Introduction to Quantitative Genetics. 4th ed. Longman Group, Essex, UK.

Fuhrer, J., and P. J. Gregory. 2014. Climate Change Impact and Adaptation in Agricultural Systems. CABI Publishing, Wallingford, UK.

Gwazdauskas, F. C. 1985. Effects of climate on reproduction in cattle. J. Dairy Sci. 68:1568-1578.

Gwazdauskas, F. C., J. A. Lineweaver, and M. L. McGilliard. 1983. Environmental and management factors affecting estrous activity in dairy cattle. J. Dairy Sci. 66:1510-1514.

Gwazdauskas, F. C., R. L. Nebel, D. J. Sprecher, W. D. Whittier, and M. L. McGilliard. 1990. Effectiveness of rump-mounted devices and androgenized females for detection of estrus in dairy cattle. J. Dairy Sci. 73:2965-2970.

Hansen, P. J., and E. R. Hauser. 1983. Genotype x environmental interactions on reproductive traits of bovine females. III. Seasonal variation in postpartum reproduction as influenced by genotype, suckling and dietary regimen. J. Anim. Sci. 56:1362-1369.

Hansen, P. J., and E. R. Hauser. 1984. Photoperiodic alteration of postpartum reproductive function in suckled cows. Theriogenology 22:1-14.

Hill, W. G., M. R. Edwards, M.-K. A. Ahmed, and R. Thompson. 1983. Heritability of milk yield and composition at different levels and variability of production. Anim. Sci. 36:59-68.

Hou, Y., P. Madsen, R. Labouriau, Y. Zhang, M. S. Lund, and G. Su. 2009. Genetic analysis of days from calving to first insemination and days open in Danish Holsteins using different models and censoring scenarios. J. Dairy Sci. 92:1229-1239.

Ismael, A., E. Strandberg, M. Kargo, A. Fogh, and P. Løvendahl. 2015 Estrus traits derived from activity measurements are heritable and closely related to the time from calving to first insemination. J. Dairy Sci. 98:3470-3477.

Kadarmideen, H. N., R. Thompson, and G. Simm. 2000. Linear and threshold model genetic parameters for disease, fertility and milk production in dairy cattle. Anim. Sci. 71:411-419.

Kolmodin, R., E. Strandberg, P. Madsen, J. Jensen, and H. Jorjani. 2002. Genotype by environment interaction in Nordic dairy cattle studied using reaction norms. Acta Agric. Scand. A Anim. Sci. $52: 11-24$. 
König, S., Y. M. Chang, U. U. v. Borstel, D. Gianola, and H. Simianer. 2008. Genetic and phenotypic relationships among milk urea nitrogen, fertility, and milk yield in Holstein cows. J. Dairy Sci. 91:4372-4382.

Løvendahl, P., and M. G. G. Chagunda. 2009. Short communication: Genetic variation in estrus activity traits. J. Dairy Sci. 92:46834688.

Løvendahl, P., and M. G. G. Chagunda. 2010. On the use of physical activity monitoring for estrus detection in dairy cows. J. Dairy Sci. 93:249-259.

Lucy, M. C. 2001. Reproductive loss in high-producing dairy cattle: Where will it end? J. Dairy Sci. 84:1277-1293.

Madsen, P., and J. Jensen. 2010. A User's Guide to DMU. Version 6, release 5. Aarhus University, Faculty of Agricultural Sciences, Aarhus, Denmark.

Meuwissen, T. H. E., G. De Jong, and B. Engel. 1996. Joint estimation of breeding values and heterogeneous variances of large data files. J. Dairy Sci. 79:310-316.

Mulder, H. A., R. F. Veerkamp, B. J. Ducro, J. A. van Arendonk, and P. Bijma. 2006. Optimization of dairy cattle breeding programs for different environments with genotype by environment interaction. J. Dairy Sci. 89:1740-1752.

Muuttoranta, K., A.-M. Tyrisevä, E. A. Mäntysaari, J. Pösö, G. P. Aamand, J.-A. Eriksson, U. S. Nielsen, and M. H. Lidauer. 2015. Genetic parameters for female fertility in Nordic dairy cattle. Interbull Bull. 49:32-35.

Nilforooshan, M. A., J. H. Jakobsen, W. F. Fikse, B. Berglund, and H Jorjani. 2009. International genetic evaluations for female fertility traits using multi-trait MACE. Interbull Bull. 39:99-102.

Oseni, S., I. Misztal, S. Tsuruta, and R. Rekaya. 2003. Seasonality of days open in US Holsteins. J. Dairy Sci. 86:3718-3725.

Oseni, S., I. Misztal, S. Tsuruta, and R. Rekaya. 2004. Genetic components of days open under heat stress. J. Dairy Sci. 87:3022-3028.

Petersson, K. J., B. Berglund, E. Strandberg, H. Gustafsson, A. P. F Flint, J. A. Woolliams, and M. D. Royal. 2007. Genetic analysis of postpartum measures of luteal activity in dairy cows. J. Dairy Sci. 90:427-434.

Petersson, K. J., E. Strandberg, H. Gustafsson, and B. Berglund. 2006. Environmental effects on progesterone profile measures of dairy cow fertility. Anim. Reprod. Sci. 91:201-214.

Pszczola, M., I. Aguilar, and I. Misztal. 2009. Short communication: Trends for monthly changes in days open in Holsteins. J. Dairy Sci. 92:4689-4696.

Ravagnolo, O., and I. Misztal. 2002. Effect of heat stress on nonreturn rate in Holstein cows: Genetic analyses. J. Dairy Sci. 85:3092-3100.
Reksen, O., A. Tverdal, K. Landsverk, E. Kommisrud, K. E. Boe, and E. Ropstad. 1999. Effects of photointensity and photoperiod on milk yield and reproductive performance of Norwegian red cattle. J. Dairy Sci. 82:810-816.

Robertson, A. 1959. The sampling variance of the genetic correlation coefficient. Biometrics 15:469-485.

Roelofs, J. B., F. J. C. M. van Eerdenburg, N. M. Soede, and B. Kemp. 2005. Pedometer readings for estrous detection and as predictor for time of ovulation in dairy cattle. Theriogenology 64:1690-1703.

Royal, M. D., A. P. F. Flint, and J. A. Woolliams. 2002. Genetic and phenotypic relationships among endocrine and traditional fertility traits and production traits in Holstein-Friesian dairy cows. J. Dairy Sci. 85:958-967.

Sae-Lim, P., H. Komen, and A. Kause. 2010. Bias and precision of estimates of genotype-by-environment interaction: A simulation study. Aquaculture 310:66-73.

Schaeffer, L. R. 1994. Multiple-country comparison of dairy sires. J. Dairy Sci. 77:2671-2678

Schaeffer, L. R. 2004. Application of random regression models in animal breeding. Livest. Prod. Sci. 86:35-45.

SEGES. 2012. Cattle Housing Design- Danish Recommendations. 5th ed, SEGES, Aarhus, Denmark.

Sewalem, A., F. Miglior, G. J. Kistemaker, P. Sullivan, and B. J. Van Doormaal. 2008. Relationship between reproduction traits and functional longevity in Canadian dairy cattle. J. Dairy Sci. 91:1660-1668.

Strandberg, E., S. Brotherstone, E. Wall, and M. P. Coffey. 2009. Genotype by environment interaction for first-lactation female fertility traits in UK dairy cattle. J. Dairy Sci. 92:3437-3446.

Sundberg, T., L. Rydhmer, W. F. Fikse, B. Berglund, and E. Strandberg. 2010. Genotype by environment interaction of Swedish dairy cows in organic and conventional production systems. Acta Agric. Scand. A Anim. Sci. 60:65-73.

Svensk Mjölk. 1999. Avelsvärden för mjölkrastjurar (Breeding values for dairy bulls). Svensk Mjölk (Swedish Dairy Association), Eskilstuna, Sweden.

Veerkamp, R. F., J. K. Oldenbroek, H. J. van der Gaast, and J. H. J. van der Werf. 2000. Genetic correlation between days until start of luteal activity and milk yield, energy balance, and live weights. J. Dairy Sci. 83:577-583.

Windig, J. J., M. P. L. Calus, B. Beerda, and R. F. Veerkamp. 2006. Genetic correlations between milk production and health and fertility depending on herd environment. J. Dairy Sci. 89:1765-1775. 